\title{
PERSPECTIVE ARTICLES
}

\section{The Weight of Evidence Does Not Support the Listing of Styrene as "Reasonably Anticipated to be a Human Carcinogen" in NTP's Twelfth Report on Carcinogens}

\author{
Lorenz R. Rhomberg, Julie E. Goodman, and Robyn L. Prueitt \\ Gradient, Cambridge, MA, USA
}

\begin{abstract}
Styrene was listed as "reasonably anticipated to be a human carcinogen" in the twelfth edition of the National Toxicology Program's Report on Carcinogens based on what we contend are erroneous findings of limited evidence of carcinogenicity in humans, sufficient evidence of carcinogenicity in experimental animals, and supporting mechanistic data. The epidemiology studies show no consistent increased incidence of, or mortality from, any type of cancer. In animal studies, increased incidence rates of mostly benign tumors have been observed only in certain strains of one species (mice) and at one tissue site (lung). The lack of concordance of tumor incidence and tumor type among animals (even within the same species) and humans indicates that there has been no particular cancer consistently observed among all available studies. The only plausible mechanism for styrene-induced carcinogenesis-a non-genotoxic mode of action that is specific to the mouse lung-is not relevant to humans. As a whole, the evidence does not support the characterization of styrene as "reasonably anticipated to be a human carcinogen," and styrene should not be listed in the Report on Carcinogens.
\end{abstract}

Key Words: styrene, weight of evidence, carcinogenicity, mode of action, metabolism.

\section{INTRODUCTION}

Styrene was listed in the twelfth edition of the National Toxicology Program's (NTP's) Report on Carcinogens (NTP 2011). In its report, NTP (2011) states: "Styrene

Received 12 August 2011; revised manuscript accepted 24 September 2011.

Address correspondence to Lorenz R. Rhomberg, Gradient, 20 University Road, Suite 5, Cambridge, MA 02138, USA. E-mail: lrhomberg@gradientcorp.com 


\section{Weight of Evidence for Styrene Carcinogenicity}

is reasonably anticipated to be a human carcinogen based on limited evidence of carcinogenicity from studies in humans, sufficient evidence of carcinogenicity from studies in experimental animals, and supporting data on mechanisms of carcinogenesis."

We submitted comments to NTP regarding its weight-of-evidence analysis assessing whether styrene should be considered a human carcinogen. These included an alternative weight-of-evidence analysis for each cancer type noted by NTP, with a comparison of risk estimates across exposure categories and studies, and a systematic evaluation of consistency and coherence with experimental and mechanistic studies (Goodman 2008, 2009; Rhomberg 2008, 2009). In this commentary, we summarize the findings of our analysis. We found that several requirements for "limited" or "sufficient" evidence are not considered by NTP, however, and the mode-of-action data do not support human carcinogenicity. As described in more detail below, the effects of styrene observed in experimental animals do not meet the standard of "sufficient evidence in animals" and the underlying mode of action is species-specific and not applicable to humans. In addition, the human data do not consistently show increased incidence of or mortality from cancer, and the epidemiology studies collectively do not support the standard of "limited evidence." Finally, there is no concordance among the human, experimental animal, and mode-of-action data. Thus, based on NTP's stated criteria, the evidence shows that styrene does not meet the standard for "reasonably anticipated to be a human carcinogen" and indeed, styrene should not be listed in the Report on Carcinogens.

\section{NTP CRITERIA FOR “LIMITED” OR “SUFFICIENT” EVIDENCE}

NTP (2011) states the following criteria for "limited" evidence of carcinogenicity in humans: "There is limited evidence of carcinogenicity from studies in humans, which indicates that causal interpretation is credible, but that alternative explanations, such as chance, bias, or confounding factors, could not adequately be excluded...." There are no precisely defined standards, however, for when the "limited" criterion is to be deemed satisfied.

It is important to realize that "limited" evidence still requires a positive finding that a causal explanation is credible; it is not simply applied when the data are inconsistent or inconclusive, and the mere presence of some positive evidence in some studies is not by itself grounds to conclude that a causal explanation is credible. Instead, when results are mixed or inconsistent, an evaluation of all of the data must consider whether it is credible to hold that a truly causal relationship exists (and the studies failing to show it do so because of chance, low statistical power, or because the true responses are somehow obscured by extraneous factors) or whether it is more credible that there is no causal effect (and the studies appearing to show an effect of exposure are in fact only showing chance findings or the effects of biases or confounding factors). Making such a judgment requires a thorough and systematic evaluation of the evidence and an evaluation of the relative plausibility of the competing explanations-actual causality partially obscured by chance or bias on the one hand versus bias and confounding creating the spurious appearance of apparent effects on the other. That is, the "limited" evidence category does not simply consist of cases for which there are some positive and some negative results; 


\section{R. Rhomberg et al.}

it is only when a case for a credible (albeit unproven) causative effect can be made that the "limited" evidence characterization should be applied.

In our view, when all the human evidence is evaluated, and the low numbers of observed cases and the lack of consistent patterns in cancer outcomes within and across cohorts, combined with concerns about co-exposures and confounding are considered, one comes to the conclusion that a causal relationship between styrene exposure and human cancer is not credible, and the standards of "limited" evidence are not met.

NTP (2011) also states the following criteria for "sufficient" evidence of carcinogenicity in experimental animals: "There is an increased incidence of malignant and/or a combination of malignant and benign tumors (1) in multiple species or at multiple tissue sites, (2) by multiple routes of exposure, or (3) to an unusual degree with regard to incidence, site, or type of tumor, or age at onset." As described in more detail below, the data show that the NTP criteria for "sufficient" evidence in animals are not met for styrene.

\section{EPIDEMIOLOGY STUDIES}

The NTP profile for styrene suggests that epidemiology studies of workers exposed to styrene show increased incidence of or mortality from lymphohematopoietic cancer and that some studies in the reinforced plastics industry provide suggestive evidence for increased incidence of or mortality due to pancreatic and esophageal tumors (NTP 2011). When considering the epidemiology evidence as a whole, however, there are no consistent associations between styrene exposure and any specific cancer type either within or among studies.

According to the Background Document (NTP 2008), the major epidemiology studies of styrene focus on 10 cohorts from the reinforced plastics and composites (RPC), styrene-butadiene latex rubber (SBR), and styrene/polystyrene (PS) industries, an occupational cohort in Finland reporting urinary concentrations of a styrene metabolite (Anttila et al. 1998), and a cohort of students who attended high school adjacent to facilities that produced synthetic styrene-butadiene (Loughlin et al. 1999; NTP 2008). The highest exposures occurred in the RPC industry, followed by the SBR industry, and then the PS industry (NTP 2008). Workers in the SBR industry were co-exposed to 1,3-butadiene, an established carcinogen. Details regarding these cohorts are shown in Table 1.

In certain studies, there were some statistically significant associations noted with some styrene exposure metrics for lymphohematopoietic, esophageal, and pancreatic cancers, but the risk estimates were not markedly large (i.e., most were below 2) and were far outnumbered by null associations for each cancer type. In addition, most analyses were based on a small number of observed cases, which resulted in unstable estimates, vis-à-vis wide confidence intervals that either included or were generally close to 1 . Furthermore, there were significant and non-significant negative associations reported for certain cancer types that were often as strong as positive associations reported for others. Just as it is unlikely that these negative associations are reflective of a protective mechanism for styrene, the few positive associations are unlikely to reflect a causal association. We have demonstrated this 


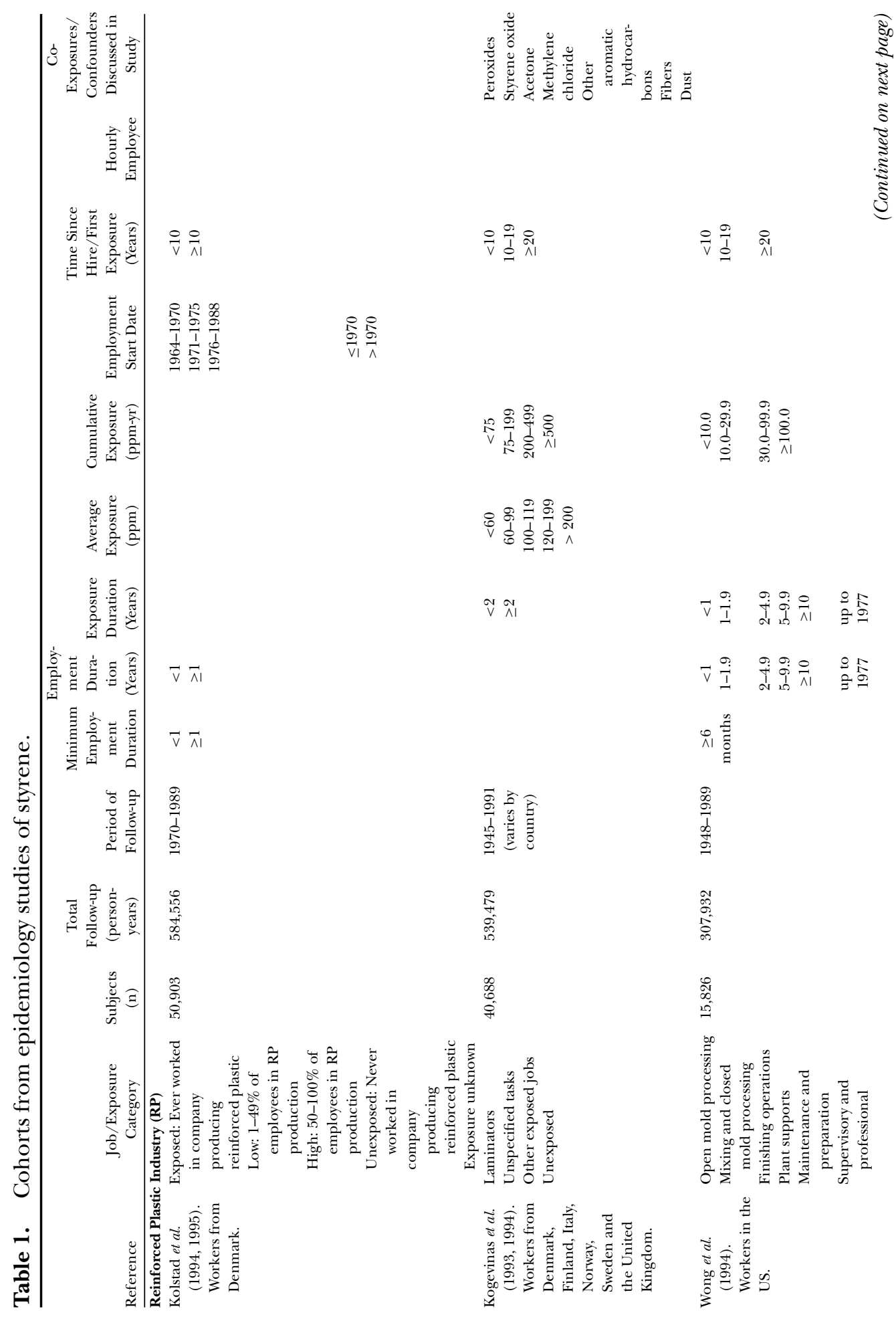




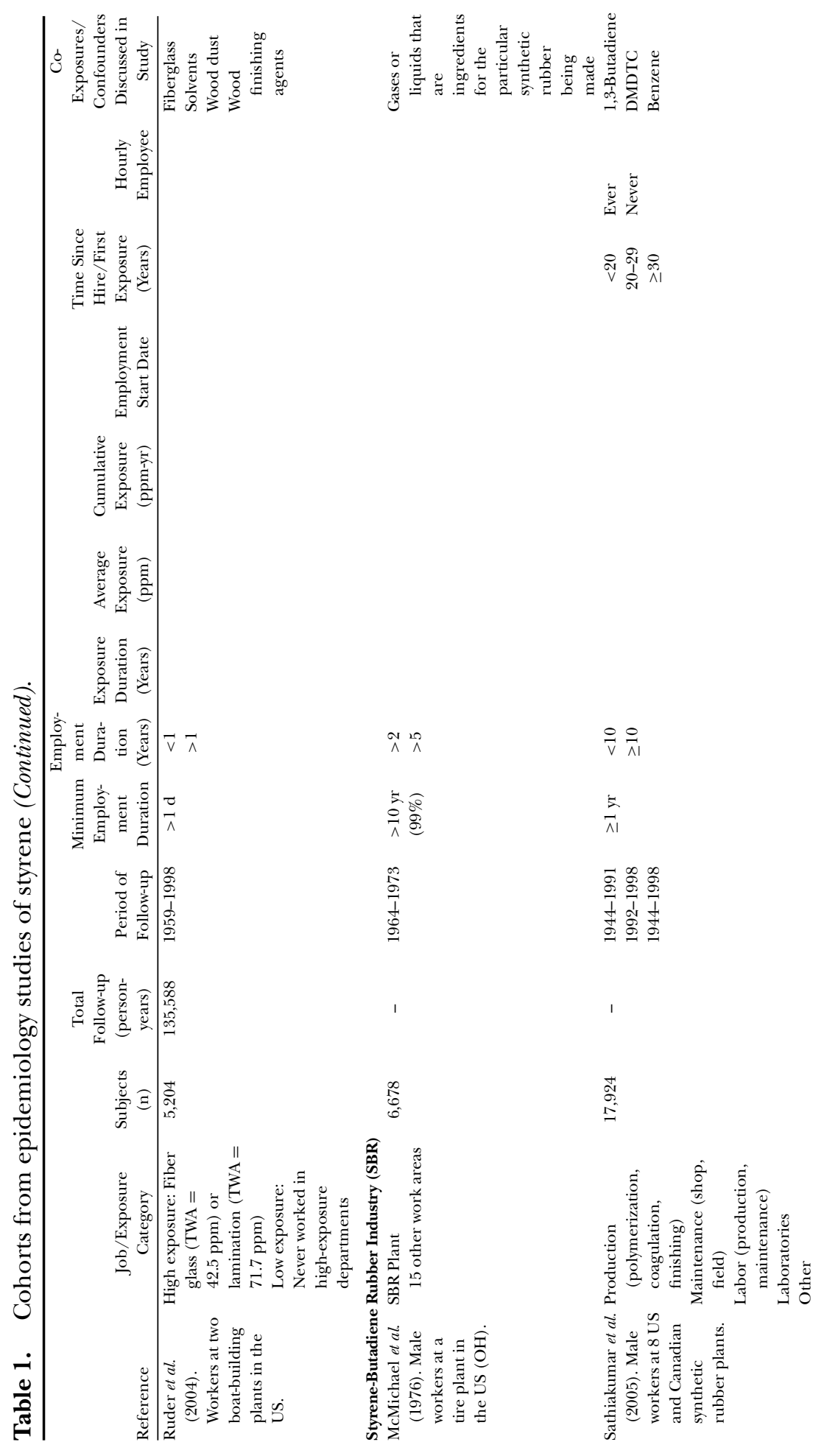




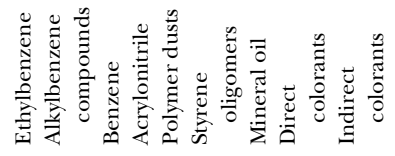

(艹)

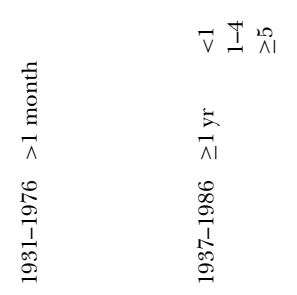

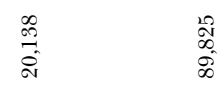

萗

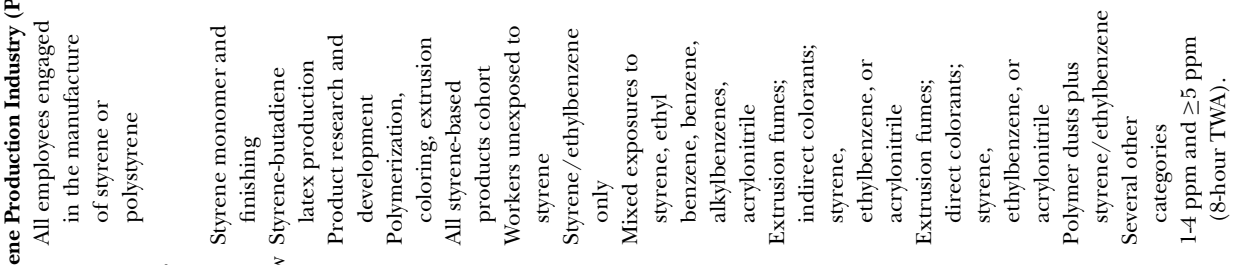

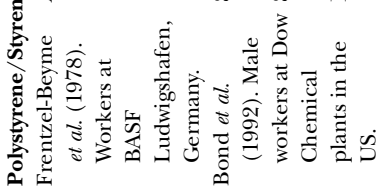




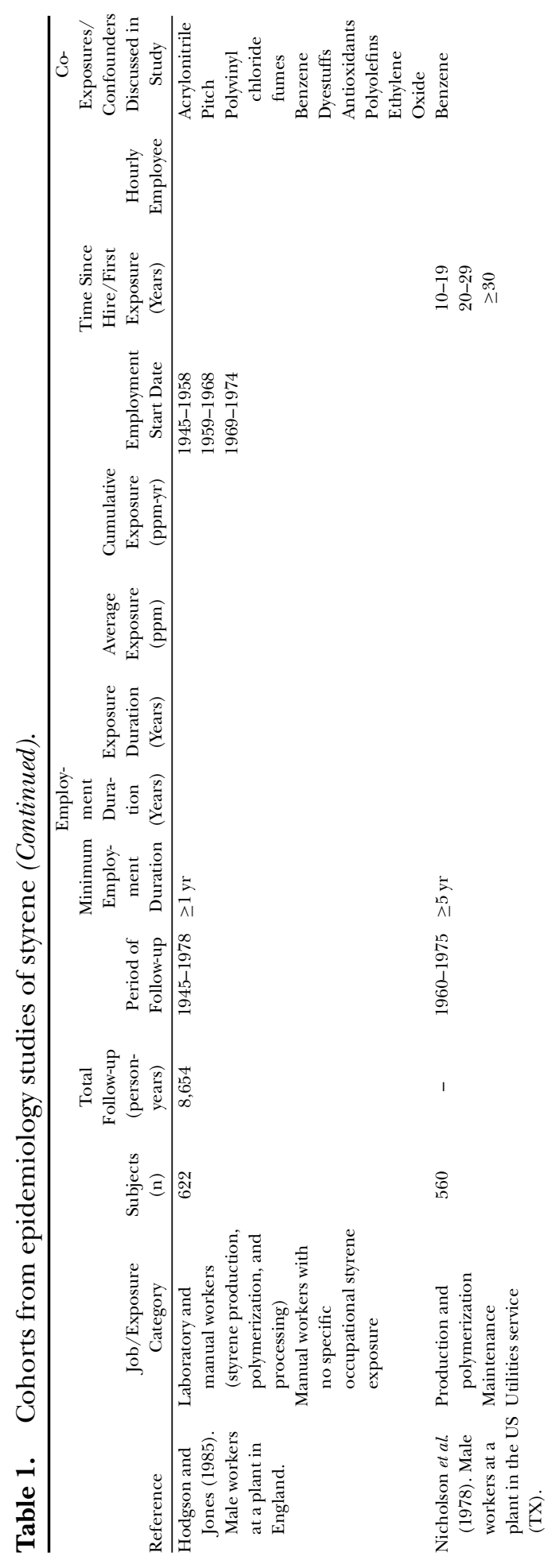


ㅇํㅅ

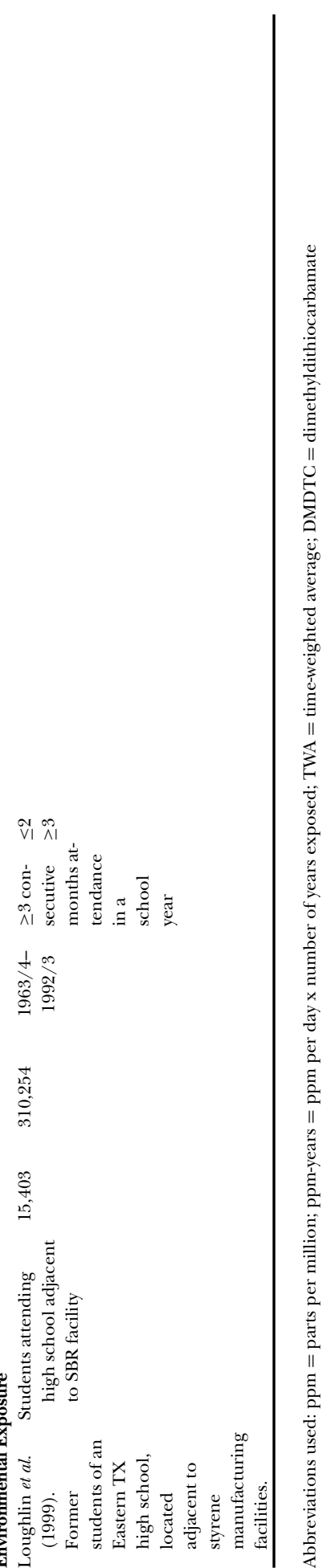




\section{R. Rhomberg et al.}

for each cancer type NTP considered in our submitted comments (Goodman 2008, 2009; Rhomberg 2008, 2009). Tables 2 and 3, which summarize the leukemia data, are provided here as an example. The weight of evidence suggests that, if there are any associations between styrene exposure and leukemia, they are not evident in the high exposure industry (RPC). There are no consistent associations seen across studies of the same cohort in the SBR industry, and co-exposure to 1,2-butadiene likely confounded results.

If styrene were associated with any cancer type, then one would expect an exposure-response relationship within studies and among industries. Studies of RPC workers should carry the greatest weight in an assessment of the epidemiology data because these workers have the highest styrene exposures. Studies of SBR workers should carry less weight because the styrene exposures are far lower, and 1,3-butadiene, even when adjusted for, cannot be completely ruled out as a confounder. As noted by Boffetta et al. (2009): "The excess leukemia mortality in the SBR industry is in line with what would be expected from exposure to the established carcinogen, 1,3-butadiene ... with no evidence for an amplified effect from the co-exposure to styrene." Stronger associations between styrene exposure and cancer risk were not observed in RPC workers. In addition, there was no indication of an increased cancer risk with increased styrene exposure within studies. Thus, when weighting these studies accordingly, the evidence for a lack of an effect becomes even stronger.

Although the NTP (2011) profile for styrene suggests increased risks for lymphohematopoietic cancers, each of these cancer types is unique, with an independent mode of action (Schottenfeld and Fraumeni 2006), and there were no consistent associations with any specific lymphohematopoietic cancer either within or across studies. Risks of other types of cancer, such as pancreatic and esophageal cancer, were also not consistently observed among studies. Taken together, the evidence does not support the profile's suggestion that styrene exposure is associated with increased incidence of, or mortality from, lymphohematopoietic, pancreatic, or esophageal cancer and does not meet the NTP criteria for "limited" evidence of carcinogenicity in humans.

\section{SPECIES-SPECIFIC EFFECTS IN EXPERIMENTAL ANIMALS}

The NTP profile for styrene states: "Styrene caused lung tumors in several strains of mice and by two different routes of exposure" (NTP 2011). There is inconsistency in the tumor incidence among different strains of mice, however, and each study that reports lung tumors in mice also suffers from limitations, as described below.

In the only chronic inhalation study of styrene in mice, with exposures of 0,20 , 40,80 , or $160 \mathrm{ppm}$ styrene vapor, increased incidence rates of bronchioalveolar adenomas (benign tumors) were observed in male and female CD-1 mice, but only at the end of the 24-month study period and with no dose-response pattern (Cruzan et al. 2001). Females exposed to the highest dose also had an increased incidence (14\%) of bronchioalveolar carcinomas (malignant tumors) at the end of the study. The historical control incidence rates of lung tumors for female CD-1 mice ranged from $0-4 \%$ for the laboratory, based on five different studies, and from $0-13.5 \%$ 
Weight of Evidence for Styrene Carcinogenicity

Table 2. Leukemia cancer risk in styrene job/exposure categories.

\begin{tabular}{|c|c|c|c|c|}
\hline Study & Job/Exposure Category & Observed & Risk Estimate $^{\mathrm{a}}$ & $95 \% \mathrm{CI}^{\mathrm{b}}$ \\
\hline \multicolumn{5}{|c|}{ Reinforced Plastic Industry $(\mathbf{R P C})^{\mathrm{c}}$} \\
\hline \multirow[t]{5}{*}{$\begin{array}{l}\text { Kolstad et al. (1994, } \\
\quad 1995)\end{array}$} & $\begin{array}{l}1-49 \% \text { employees in } \\
\text { reinforced plastics }\end{array}$ & 28 & 1.15 & $0.77-1.67$ \\
\hline & $\begin{array}{l}50-100 \% \text { employees in } \\
\text { reinforced plastics }\end{array}$ & 14 & 1.38 & $0.75-2.32$ \\
\hline & Total Reinforced plastics & 42 & 1.22 & $0.88-1.65$ \\
\hline & No reinforced plastics & 13 & 0.86 & $0.46-1.47$ \\
\hline & Production unclassified & 6 & 2.37 & $0.87-5.16$ \\
\hline \multirow{5}{*}{$\begin{array}{l}\text { Kogevinas } \text { et al. } \\
\quad(1993,1994)\end{array}$} & Laminators & 3 & 0.48 & $0.10-1.39$ \\
\hline & Unspecified Tasks & 16 & 1.4 & $0.79-2.28$ \\
\hline & Other exposed Jobs & 4 & 0.94 & $0.26-2.40$ \\
\hline & Unexposed & 4 & 0.99 & $0.27-2.54$ \\
\hline & Total & 28 & 1.04 & $0.69-1.50$ \\
\hline \multirow[t]{7}{*}{ Wong et al. $(1994)^{\mathrm{d}}$} & Open mold processing & 1 & 0.9 & \\
\hline & $\begin{array}{l}\text { Mixing and closed mold } \\
\text { processing }\end{array}$ & 0 & - & \\
\hline & Finishing operations & 2 & 0.8 & \\
\hline & Plant supports & 1 & 0.56 & \\
\hline & $\begin{array}{l}\text { Maintenance and } \\
\text { preparation }\end{array}$ & 1 & 0.48 & \\
\hline & $\begin{array}{l}\text { Supervisory and } \\
\text { professional }\end{array}$ & 1 & 1.33 & \\
\hline & Total & $11^{\mathrm{e}}$ & 0.74 & $0.37-1.32$ \\
\hline \multirow[t]{3}{*}{ Ruder et al. (2004) } & High Exposure & 1 & $0.46^{\mathrm{f}}$ & $0.01-2.58$ \\
\hline & Low Exposure & 4 & $0.64^{\mathrm{f}}$ & $0.17-1.63$ \\
\hline & Total & 5 & $0.59^{\mathrm{f}}$ & $0.19-1.38$ \\
\hline \multicolumn{5}{|c|}{ Styrene-Butadiene Rubber Industry (SBR) ${ }^{c}$} \\
\hline \multirow[t]{9}{*}{$\begin{array}{l}\text { Sathiakumar et al. } \\
\quad \text { (2005) }\end{array}$} & $\begin{array}{l}\text { Production, } \\
\text { polymerization }\end{array}$ & 18 & 2.04 & $1.21-3.22$ \\
\hline & Production, coagulation & 10 & 2.31 & $1.11-4.25$ \\
\hline & Production, finishing & 19 & 1.56 & $0.94-2.44$ \\
\hline & Maintenance, shop & 4 & 0.93 & $0.25-2.38$ \\
\hline & Maintenance, field & 10 & 0.84 & $0.40-1.55$ \\
\hline & Labor, production & 4 & 1.23 & $0.34-3.15$ \\
\hline & Labor, maintenance & 15 & 2.03 & $1.14-3.35$ \\
\hline & Laboratories & 14 & 3.26 & $1.78-5.46$ \\
\hline & Other operations & 6 & 0.69 & $0.25-1.50$ \\
\hline \multirow[t]{4}{*}{$\begin{array}{l}\text { McMichael et al. } \\
\qquad(1976)^{\mathrm{g}}\end{array}$} & $\begin{array}{l}\text { Compounding, mixing: } \\
\text { cement mixing }\end{array}$ & & 1.3 & $1.0-1.8$ \\
\hline & $\begin{array}{l}\text { Extrusion, tread } \\
\text { cementing }\end{array}$ & & 3.2 & $2.4-5.0$ \\
\hline & $\begin{array}{l}\text { Inspection, finishing, } \\
\text { repair }\end{array}$ & & 3.7 & $2.8-5.3$ \\
\hline & Synthetic plant & & 3.9 & $2.6-8.0$ \\
\hline
\end{tabular}




\section{R. Rhomberg et al.}

Table 2. Leukemia cancer risk in styrene job/exposure categories (Continued).

\begin{tabular}{|c|c|c|c|c|}
\hline Study & Job/Exposure Category & Observed & Risk Estimate $^{\mathrm{a}}$ & $95 \% \mathrm{CI}^{\mathrm{b}}$ \\
\hline \multicolumn{5}{|c|}{ Polystyrene/Styrene Production Industry (PS) } \\
\hline \multirow[t]{5}{*}{ Bond et al. $(1992)^{\mathrm{d}}$} & $\begin{array}{l}\text { Styrene monomer and } \\
\text { finishing }\end{array}$ & 1 & $--^{\mathrm{h}}$ & \\
\hline & $\begin{array}{l}\text { Styrene-butadiene latex } \\
\text { production }\end{array}$ & 1 & $-{ }^{\mathrm{h}}$ & \\
\hline & $\begin{array}{l}\text { Product research and } \\
\text { development }\end{array}$ & 1 & $-^{\mathrm{h}}$ & \\
\hline & $\begin{array}{l}\text { Polymerization, coloring, } \\
\text { extrusion }\end{array}$ & 6 & 1.65 & \\
\hline & Total & 9 & 1.18 & $0.54-2.24$ \\
\hline \multirow{3}{*}{$\begin{array}{l}\text { Hodgson and Jones } \\
\quad(1985)\end{array}$} & Exposed workers & 0 & - & \\
\hline & Unexposed workers & 0 & - & \\
\hline & Total & $1^{\mathrm{f}}$ & $-{ }^{\mathrm{h}}$ & \\
\hline $\begin{array}{l}\text { Nicholson et al. } \\
\text { (1978) }\end{array}$ & Total & 1 & $1 / 0.79$ & \\
\hline \multicolumn{5}{|c|}{ Environmental Exposure ${ }^{c}$} \\
\hline \multirow{2}{*}{$\begin{array}{l}\text { Loughlin et al. } \\
\text { (1999) }\end{array}$} & Men & 6 & 1.82 & $0.67-3.96$ \\
\hline & Women & 1 & 0.45 & $0.01-2.48$ \\
\hline
\end{tabular}

${ }^{a}$ Risk estimates were reported as one of the following: standardized mortality ratio (SMR), standardized incidence ratio (SIR), relative risk (RR), or standardized risk ratio (SRR).

Some values were divided by 100 for comparison.

${ }^{\mathrm{b}} 95 \% \mathrm{CI}=95 \%$ confidence interval.

'Statistically significant findings indicated in bold.

${ }^{\mathrm{d}}$ If $95 \%$ CI was not provided, statistical significance was indicated in study.

${ }^{\mathrm{e}}$ The total includes the entire study cohort, it is not the sum of all the observed cases by exposure category.

${ }^{\mathrm{f}}$ Compared to the US population. Similar results when compared to Washington state population.

${ }^{\mathrm{g}}$ McMichael et al. (1976) calculated 99.9\% CIs and did not report non-significant associations.

${ }^{\mathrm{h}} \mathrm{SMR}$ not calculated by authors if observed $<3$.

for the animal supplier (Charles River), based on nine different studies (Cruzan et al. 2001). The adenomas and carcinomas did not differ in tumor morphology between control and treated mice, and histopathologic changes were observed in the terminal bronchioles at all exposure concentrations at 12-, 18-, and 24-month time points. These changes included decreased eosinophilic staining of Clara cells and epithelial hyperplasia that extended into the alveolar ducts.

In a chronic oral gavage study, male B6C3F1 mice were treated with 0,150 , or $300 \mathrm{mg} / \mathrm{kg}$-day styrene in corn oil (NCI 1979). Males treated with the highest dose of styrene showed an increased incidence (18\%) of combined bronchioalveolar adenomas and carcinomas. The tumors were only observed at the end of the 21month study period, and there was no increase in tumor incidence in females in any 


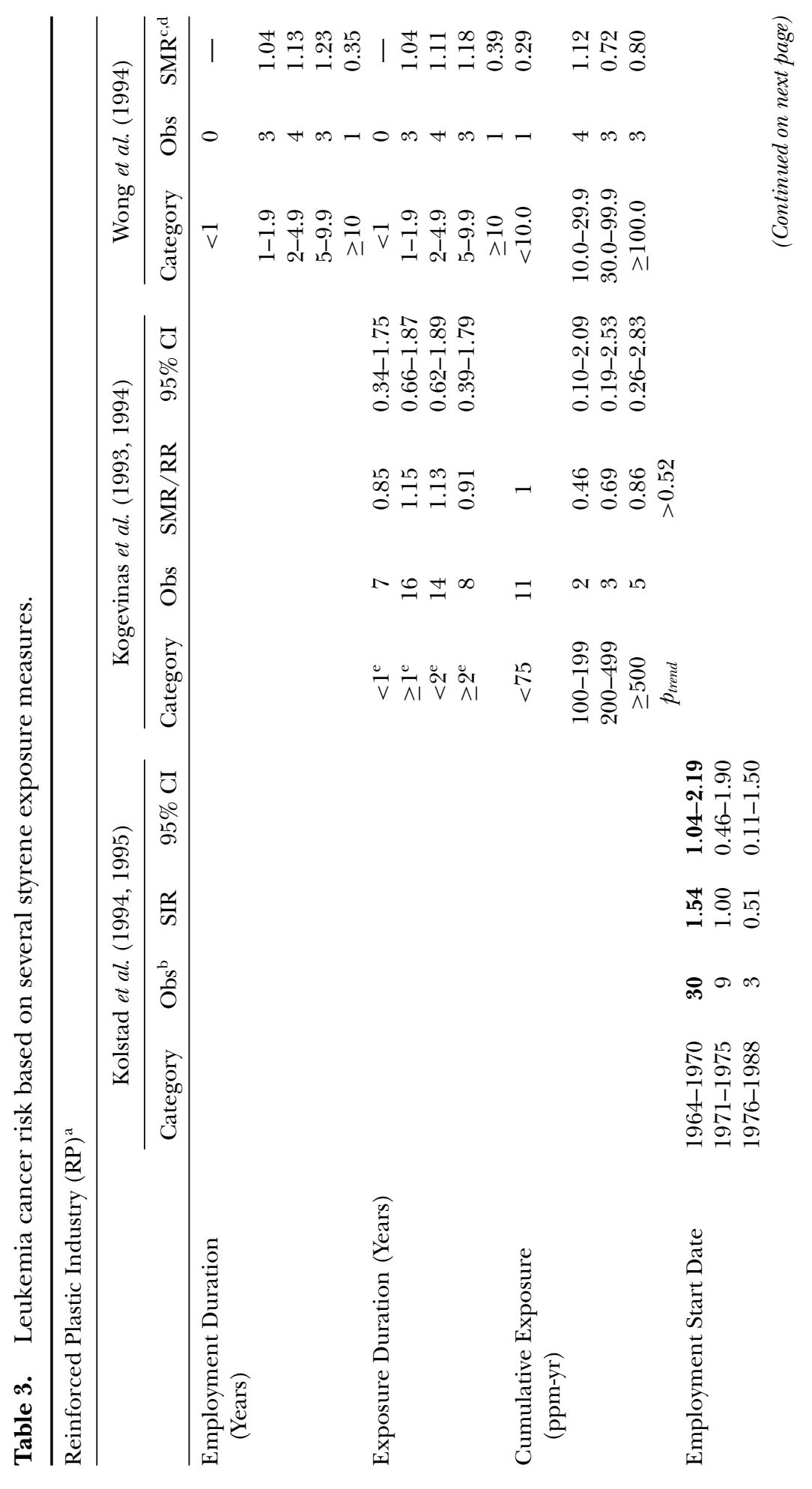




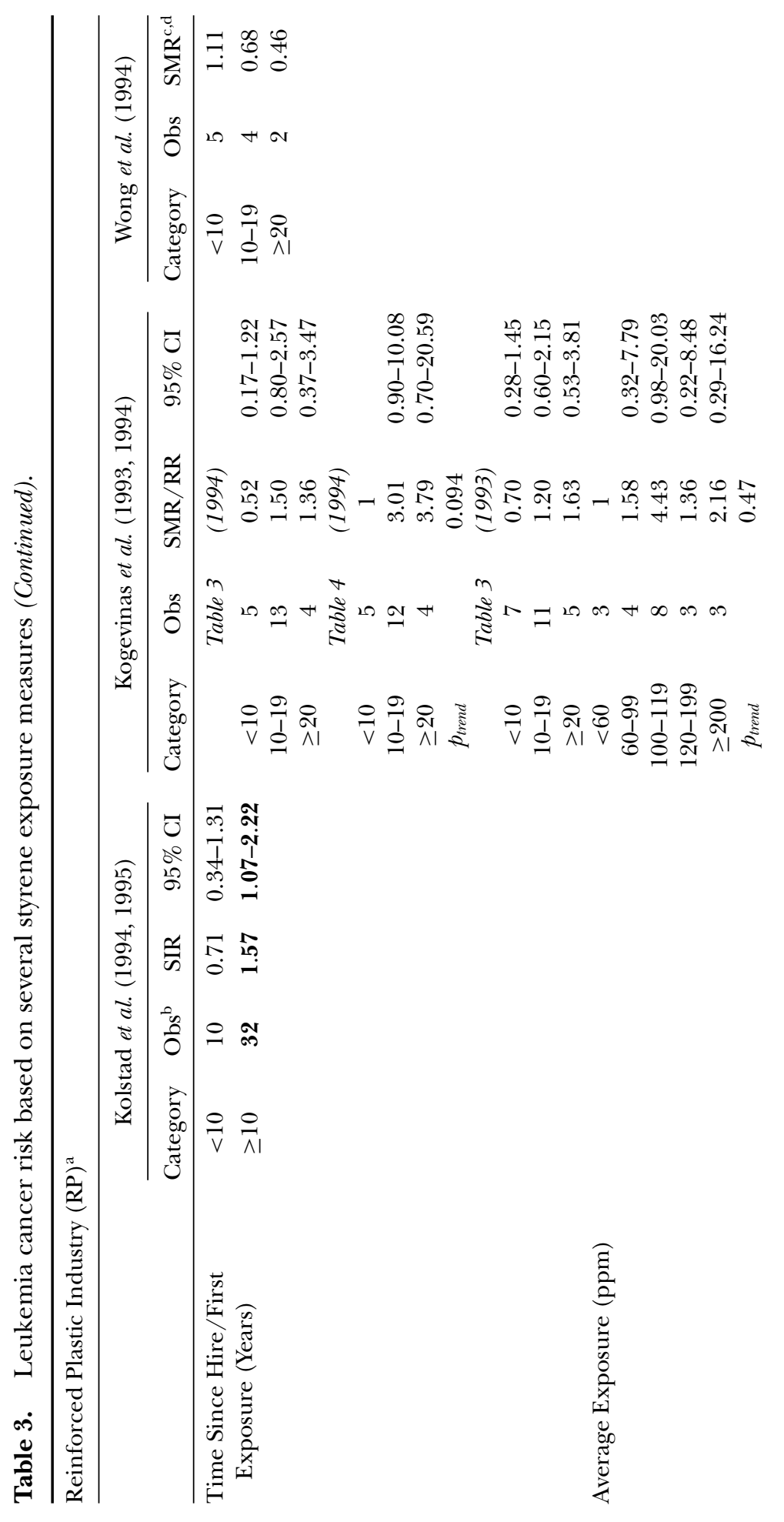




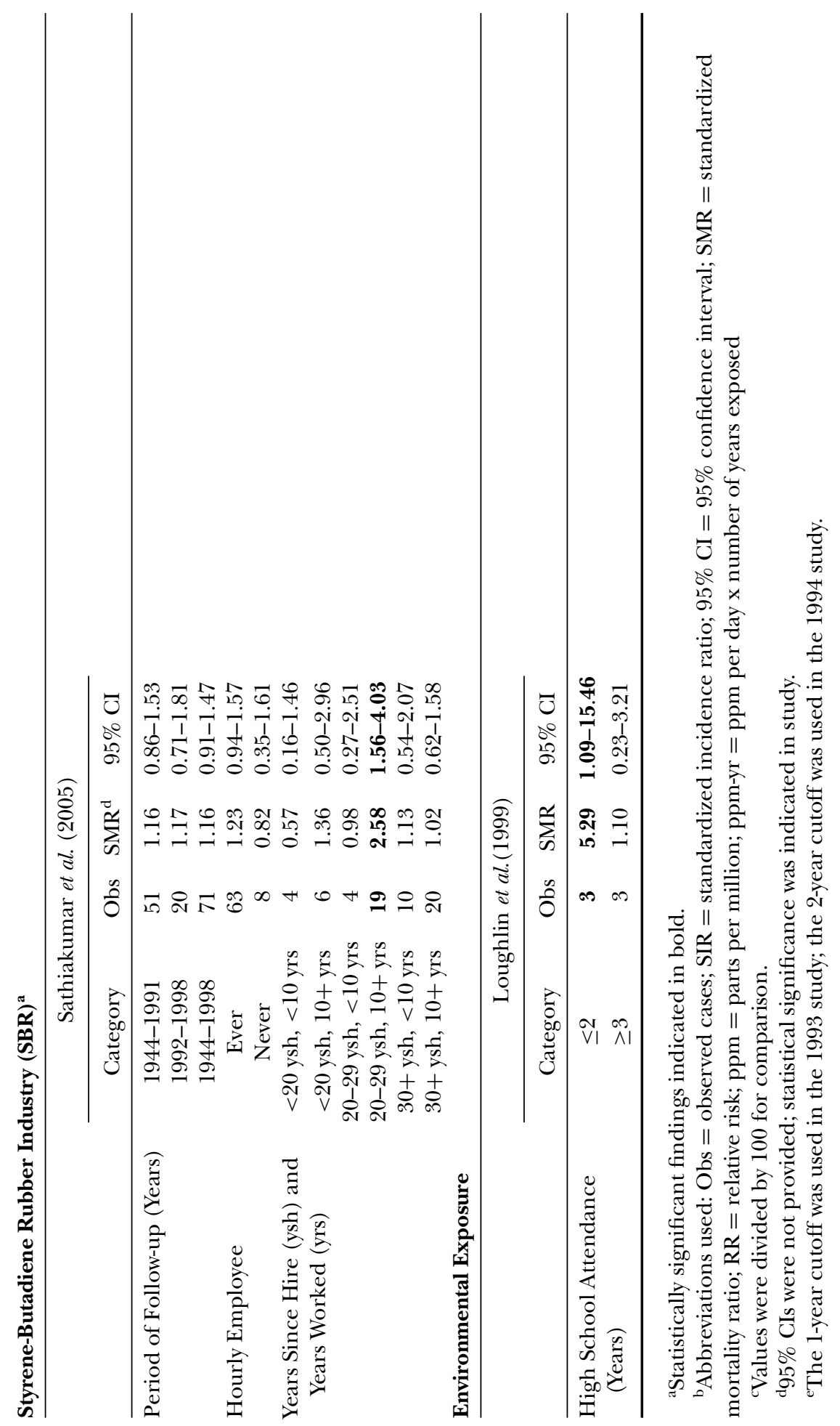




\section{R. Rhomberg et al.}

dose group. No lung tumors were observed in the 20 vehicle controls, even though the historical control incidence for untreated controls at the laboratory ranged from $0-20 \%$. NCI determined that the historical control data were insufficient for vehicle-treated controls. The Background Document (NTP 2008) examined vehicle controls from two studies in the same laboratory (Litton Bionetics), as well as 14 studies from a nearby laboratory (Hazleton Laboratories), and concluded that the tumor incidence in high dose males in the styrene study could be considered as outside the historical control range. The use of historical controls from a different testing laboratory is not scientifically supported, however. Other investigators have recommended that historical control comparisons should only use controls from the same testing laboratory because of the statistically significant inter-laboratory variability that has been observed in control mouse lung tumor incidence (Haseman et al. 1984). Thus, the new historical control data used by NTP are not valid for assessing the NCI study. Because of the discrepancy in control incidence and the tumor response at only one site and in one sex, NCI (1979) concluded that "under the conditions of this bioassay, no convincing evidence for the carcinogenicity of the compound was obtained in ... B6C3F1 mice of either sex."

In other chronic oral gavage studies, an increased incidence of combined adenomas and carcinomas was observed in the lungs of male and female $\mathrm{O}_{20}$ mice treated with $1,350 \mathrm{mg} / \mathrm{kg}$ styrene in olive oil (Ponomarkov and Tomatis 1978). Treatment with this dose of styrene was associated with the presence of severe lung congestion and early mortality; the average age of death for treated males and females was 32 and 49 weeks, respectively, compared to 88 and 85 weeks, respectively, for the male and female vehicle controls. These results indicate possible styrene toxicity as a complicating factor. Lung tumors were observed in 20/23 (87\%) of styrene-treated males and $32 / 32(100 \%)$ of styrene-treated females, compared to 8/19 (42\%) of male and 14/21 (67\%) of female vehicle controls, after adjusting for early mortality. Lung tumors were also observed in 34/53 (64\%) of male and 25/47 (53\%) female untreated controls, indicating that the $\mathrm{O}_{20}$ mouse strain is particularly sensitive to the induction of lung tumors. The incidence in the styrene-treated males was significantly higher than the vehicle controls only, whereas in styrene-treated females, the incidence was significantly higher than both control groups. The authors concluded: "The increased incidence and early appearance of lung tumors could possibly indicate a carcinogenic effect for styrene in $\mathrm{O}_{20}$ mice. This experiment, however, has severe limitations, since the dose used was obviously very high, causing severe toxic effects and an early mortality. Results from additional studies are needed before a final evaluation of the carcinogenicity of styrene in rodents can be made" (Ponomarkov and Tomatis 1978). The same authors, using a similar study design, and a dose of $300 \mathrm{mg} / \mathrm{kg}$ styrene reported no increase in the incidence of tumors of any type in styrene-treated male and female C57Bl mice (Ponomarkov and Tomatis 1978).

In addition to the inhalation and oral gavage studies, styrene carcinogenicity was examined in mice after parenteral exposure. Although not a two-year carcinogenicity study, intraperitoneal injection of styrene into A/J mice for seven weeks did not result in an increased incidence of lung or other types of tumors at sacrifice 20 weeks later (Brunnemann et al. 1992). 


\section{Weight of Evidence for Styrene Carcinogenicity}

There were no increased tumor incidence rates reported in seven chronic rat studies of styrene that used various rat strains and exposure routes, including inhalation exposure in Sprague-Dawley (SD) rats (Cruzan et al. 1998; Conti et al. 1988; Jersey et al. 1978), oral gavage in SD, F344, and BD IV rats (Conti et al. 1988; NCI 1979; Ponomarkov and Tomatis 1978), and drinking water in SD rats (Beliles et al. 1985). The NTP profile for styrene states: "The evidence from studies in rats is insufficient for reaching a conclusion concerning the carcinogenicity of styrene" (NTP 2011). That is, there is a lack of generality of the tumorigenic response among rodent species. It is unclear why NTP did not consider negative rat bioassay results as evidence against styrene's general carcinogenicity.

In summary, there is evidence that styrene causes an increased incidence of lung tumors in mice after inhalation exposure. Other studies in mice that used oral gavage as the exposure route were equivocal, and tumor incidence was not increased in one study that used intraperitoneal injection. Thus, an increased tumor incidence caused by styrene exposure has only been observed in one experimental animal species and at one tissue site. The tumors observed in mice after inhalation of styrene were mostly benign and occurred at the end of the chronic study period, causing no early mortality. In addition, the tumors were observed in the presence of lung toxicity in mouse strains with a high background incidence of lung tumors (Cruzan et al. 2001). Taken together, the animal data for styrene do not meet the NTP criteria for "sufficient" evidence of carcinogenicity in experimental animals. Neither lung toxicity nor lung tumors have been observed in humans exposed to styrene and, as described below, the proposed mode of action for styreneinduced lung tumors in mice is not applicable to humans, or even to other rodent species.

\section{MODE-OF-ACTION DATA}

As noted above, styrene induces lung toxicity in mice, but not in rats or humans. In this section, the mode-of-action data that indicate the species-specific origin of this toxicity and how this toxicity is the likely cause of tumor formation in the mouse lung are described. These data include the results of studies examining differences in styrene metabolism across species and localized metabolism of styrene in the mouse lung, as well as genotoxicity data that strongly suggest a non-genotoxic mode of action for styrene-induced lung tumors in mice.

Inhalation exposures to styrene induce lung toxicity and subsequent tumors in mice and nasal toxicity without tumor development in mice and rats (Cruzan et al. 1997, 1998, 2001). Lung toxicity has been reported as decreased cytoplasmic staining and increased replication of Clara cells of the mouse bronchiolar epithelium, cell crowding in the terminal bronchioles, decreased eosinophilia of the mouse bronchiolar epithelium, and hyperplasia of Clara cells in the terminal bronchioles (Cruzan et al. 1997, 2001; Green et al. 2001b; Roycroft et al. 1992). In a chronic inhalation study, Cruzan et al. (2001) observed a progression from decreased eosinophilia to hyperplasia of the terminal bronchiolar epithelium, and finally, to hyperplasia that extended into the alveolar ducts. With increasing duration, the exposure 


\section{R. Rhomberg et al.}

concentration at which effects were seen also decreased, such that mice in each dose group were affected by the end of the study.

The differences in styrene-induced toxicity among mice, rats, and humans can be explained by differences in styrene metabolism. Styrene metabolism occurs mainly in the liver and the lung, and results primarily in the formation of the weakly genotoxic metabolite, styrene-7,8-oxide (SO) (IARC 2002). SO can be detoxified by glutathione conjugation or by conversion to styrene glycol by microsomal epoxide hydrolase (IARC 2002). Styrene can also be metabolized by conversion to phenylacetic and phenylaceturic acids (PAA pathway), or by oxidation of its benzene ring, which can lead to the formation of 4-vinylphenol (4-VP) (IARC 2002). Based on measurements of urinary metabolites, humans metabolize styrene almost exclusively via the SO-epoxide hydrolase pathway (Johanson et al. 2000). The ring oxidation and PAA pathways play very small roles in styrene metabolism in humans and are used much more in the metabolism of styrene in mice than in rats, indicating that there are major species differences in the overall metabolism of styrene (Johanson et al. 2000; Sumner et al. 1997).

The formation of SO from styrene is catalyzed by cytochrome P450. While CYP2E1 is the predominant enzyme for styrene metabolism in the liver, metabolism by CYP2F (2F1 in humans, 2F2 in mice, and 2F4 in rats) is necessary for toxicity to occur in the lung (Hynes et al. 1999; Wenker et al. 2001; Shen et al. 2011; Cruzan et al. 2011). There are significant species differences with respect to the activities and concentrations of the CYP2F enzymes in the lung. In mice and rats, the CYP2F enzymes readily metabolize styrene, whereas in humans, CYP2F1 does not appear to metabolize styrene at all (Green et al. 2001a). Clara cells are the major cell type in the lung that metabolizes styrene to SO following inhalation exposure, and in mice, these cells are numerous and are spread throughout the airways (Green 2000). In rats, they are significantly fewer in number, particularly in the terminal bronchiolar region (Green 2000). In humans, Clara cells are rare and can be found in small numbers in the distal bronchioles (Green 2000). Hynes et al. (1999) demonstrated that mouse Clara cells produce five times more SO than rat Clara cells. Thus, the cells that metabolize styrene in the lung differ in their number, location, and specificity among mice, rats, and humans.

Physiologically-based pharmacokinetic (PBPK) modeling has shown that the target tissue concentration of SO is primarily due to localized tissue metabolism of styrene rather than delivery of SO to the lung via the arterial blood (Sarangapani et al. 2002). This model also predicted that at a given airborne concentration of styrene, the level of total SO in mouse terminal bronchioles is approximately 10 times higher than in rats and 100 times higher than in humans (Sarangapani et al. 2002). Evidence that local metabolism of styrene is responsible for the lung toxicity of styrene is given by the fact that circulating levels of SO do not correlate with lung tumor incidence. Blood levels of SO were much higher in rats at non-tumorigenic concentrations than in mice at levels associated with an increased incidence of lung tumors (Cruzan et al. 1998, 2001). In addition, metabolism and cytotoxicity occur in the mouse lung after oral exposure to styrene (Green et al. 2001b), indicating that systemically absorbed concentrations of styrene are preferentially metabolized in the mouse lung.

A recent study using Cyp2f2 knockout mice demonstrated that both styrene and SO toxicity in the mouse lung require CYP2F2 metabolism (Cruzan et al. 2011). 


\section{Weight of Evidence for Styrene Carcinogenicity}

Studies in mice using a CYP2F2 inhibitor have also shown that metabolism of styrene by CYP2F2 is necessary to cause lung toxicity (Green et al. 2001a,b). Inhibition of CYP2F2 also inhibited the cytotoxicity of 4-VP (Carlson 2002), which is 10 times as toxic to the mouse lung as styrene and 5 times as toxic as SO (Carlson et al. 2002). Because 4-VP can be metabolized by CYP2F2 into further ring-oxidized metabolites of styrene (Carlson et al. 2001; Shen et al. 2011), this indicates that there is a subsequent metabolite of 4 -VP that is responsible for lung cytotoxicity in mice. As mentioned above, the ring oxidation pathway of styrene metabolism is more predominant in mice than in rats or humans, and it has been shown that intraperitoneal administration of 4-VP induced cytotoxicity in the terminal bronchioles of mice, but not rats (Cruzan et al. 2005).

The NTP profile for styrene states that the proposed mechanisms for the carcinogenicity of styrene include both genotoxic and non-genotoxic pathways. Extensive data show, however, that a genotoxic mode of action for styrene is unlikely.

Although SO can adduct to proteins and DNA, low levels of SO-DNA adducts have been observed in vivo. Increases in SO-DNA adducts have not been observed in mouse versus rat lung or mouse lung versus mouse liver after inhalation exposure to styrene; thus, the increased incidence of lung tumors in mice is not accompanied by an increase in DNA adducts (Boogaard et al. 2000; Cruzan et al. 2002).

The genotoxicity data for styrene are inconsistent (as reviewed by IARC 2002). The mutagenicity data have been negative or weakly positive. There have been some positive results from in vitro assays for chromosomal effects, but in vivo studies do not indicate increases in chromosomal aberrations or micronuclei. A small increase in sister chromatid exchanges (SCEs) has been observed in experimental animal studies of styrene, but in humans there has been no observed increase in SCEs in a dose-responsive manner. In a study by Vodicka et al. (2004), there was no clear association between styrene exposure and chromosomal aberrations, micronuclei, single strand breaks, and DNA repair in styrene-exposed workers.

Although SO is directly genotoxic in vitro, oral administration of SO to mice and rats did not lead to systemic tumors, despite producing systemic concentrations of SO that were equal to or higher than those resulting from inhalation exposures (Sarangapani et al. 2002). In both species, tumors were only observed at the site of contact, the forestomach (Conti et al. 1988; Lijinsky 1986; Ponomarkov et al. 1984). In these studies, oral exposure to SO also induced cell damage, repair, and increased proliferation, suggesting that the mechanism for tumor formation by SO in the forestomach is attributable to the increased cell proliferation resulting from the cellular damage induced by SO. This type of non-genotoxic mechanism of action may also explain the increased lung tumor incidence in mice after chronic exposure to styrene.

A non-genotoxic mode of action for styrene-induced lung tumors in mice is the most plausible mechanism for styrene carcinogenicity. Increased tumor incidence caused by styrene exposure has only been observed in one species and at one tissue site. The tumors were mostly benign and were observed late in life, causing no early mortality. Tumors were accompanied by organ toxicity and cell turnover, in the form of Clara cell damage and proliferation. Further support for a non-genotoxic mode of action comes from a 20 -week study in which styrene exposure via intraperitoneal injection did not induce tumors of any type in mice 


\section{R. Rhomberg et al.}

(Brunnemann et al. 1992), suggesting that styrene cannot initiate tumorigenesis. In addition, target organ metabolism of styrene is necessary for the observed toxicity and tumor formation, as oral administration of the genotoxic primary metabolite, $\mathrm{SO}$, does not induce systemic tumors, and circulating levels of SO are not associated with increased tumor incidence. The genotoxicity data for styrene are inconsistent, and DNA adducts are observed at low levels after exposure and are not associated with tumor incidence.

The mechanistic evidence that suggests a specific, non-genotoxic mode of action for styrene in the responding animals is of questionable applicability to other animals, other tissues, and to humans. Styrene-induced cytotoxicity occurs in organs with high levels of the CYP2F family of enzymes. Mouse lungs have a larger fraction of CYP2F2-containing Clara cells than rat or human lungs, and the metabolism rates of styrene by the CYP2F family are higher in mice than in rats and are virtually non-existent in humans. In addition, styrene metabolites are removed more rapidly in rat and human tissues compared to mouse tissues (Green et al. 2001a). Consistent with these data, no styrene-induced toxicity, hyperplasia, or tumors have been observed in rat or human lungs. Because the levels of CYP2F enzymes are higher in rat lungs compared to human lungs, the lack of lung toxicity or tumor formation in rats makes it very unlikely that a chemical that causes lung tumors by this mode of action in mice, but not rats, will cause human lung tumors. In accordance with the preceding mechanistic information, epidemiology data do not show an increased incidence of lung cancer, or any cancer type, in humans exposed to styrene.

\section{LACK OF CONCORDANCE AMONG HUMAN, EXPERIMENTAL ANIMAL, AND MODE-OF-ACTION DATA}

The NTP (2011) profile for styrene states that: "Although styrene disposition differs quantitatively among species, no qualitative differences between humans and experimental animals have been demonstrated that contradict the relevance of cancer studies in rodents for evaluation of human hazard. Detection of styrene-7,8-oxideDNA adducts at base-pairing sites and chromosomal aberrations in lymphocytes of styrene-exposed workers supports the potential human cancer hazard from styrene through a genotoxic mode of action." This statement is incorrect for several reasons, as described below.

There is no concordance among the human, rodent, and mode-of-action data on the effects of styrene. The styrene-induced lung toxicity and tumor formation observed in mice are species-specific, and the mechanistic data strongly suggest that these tumors result from the lung toxicity that depends upon the localized metabolism of styrene by mouse CYP2F2. In humans, CYP2F1 does not appear to metabolize styrene. In addition, the metabolic pathway resulting in the formation of 4-VP, which may be the substrate for the CYP2F2-dependent cytotoxic metabolite in mouse lung, is a minor pathway in humans compared to mice. There is substantial evidence that the SO mutagenicity, cited by the NTP (2011) profile as the basis for applying the mouse results to human risk projection, is not an important factor in vivo even in animals, is not consistent with the localization of mouse tumors, and in fact is not responsible for the mouse tumor response. Thus, the ability of humans to form SO is not germane. 


\section{Weight of Evidence for Styrene Carcinogenicity}

The epidemiology data as a whole do not suggest that styrene exposure is associated with any specific cancer type in humans, either within or among studies. The NTP profile, however, interprets these data as suggesting that styrene exposure increases the incidence of lymphohematopoietic cancers, and possibly pancreatic and esophageal cancers, in humans (NTP 2011). Even if one accepts this interpretation, there have been no corresponding responses observed in experimental animals, as no increased incidences of lymphohematopoietic, pancreatic, or esophageal tumors have been reported in styrene-exposed animals. The experimental animal data also indicate that orally-administered styrene does not induce tumors systemically; although the data are unclear, in some studies with inhalation and oral exposures, an increased incidence of tumors was observed specifically in the mouse lung.

The studies in which SO-DNA adducts and chromosomal aberrations were detected in styrene-exposed workers do not support a carcinogenic role for styrene. These studies are limited by their small size and lack of controlling for potential confounders. In addition, styrene-exposed rodents form similar DNA adducts, with higher levels observed in rats than in mice, suggesting that these adducts are not associated with an increased incidence of tumors (Boogaard et al. 2000; Cruzan et al. 2002). Furthermore, agents that are known or expected to cause lymphohematopoietic cancers in humans are believed to act through immune dysregulation and not through DNA damage (Alexander et al. 2007).

A genotoxic mode of action for styrene, either in animals or in humans, is not plausible. Besides the genotoxicity data for styrene being inconsistent, styrene exposure has been associated with an increased tumor incidence in only one species and one site, mouse lung. The late onset and mostly benign lung tumors observed in mice were accompanied by lung cytotoxicity and cell proliferation and were dependent on lung-specific metabolism of styrene. These data suggest a non-genotoxic mechanism of action attributable to increased cell proliferation in the mouse lung resulting from the cellular damage induced upon styrene metabolism.

Taken together, the human, experimental animal, and mode-of-action data for the effects of styrene do not support the classification of styrene as a human carcinogen. The lack of correspondence of tumor incidence and tumor type among rodents, even within the same species, and humans indicates that there has been no particular type of cancer consistently observed among all available studies and renders the argument for the human carcinogenicity of styrene as implausible. The various data indicate that the only plausible mechanism for styrene-induced carcinogenesis is a non-genotoxic mode of action that is specific to the mouse lung.

\section{CONCLUSIONS}

The NTP (2011) classification of styrene as "reasonably anticipated to be a human carcinogen" based on "limited" evidence of carcinogenicity in humans, "sufficient" evidence of carcinogenicity in animals, and supporting mechanistic data is not scientifically supported, given that the available data do not meet these criteria. Because of this, styrene should not be listed in NTP's Report on Carcinogens.

The rationale for using rodent bioassay results as indicators of possible human carcinogenicity rests on the broad similarity among mammals in anatomy, physiology, and biochemistry; the applicability of a rodent response as an indicator of potential 


\section{R. Rhomberg et al.}

human risk amounts to hypothesizing that, owing to this underlying commonality, the carcinogenic processes responsible for the animal results could also plausibly occur in humans. That is, one is hypothetically generalizing the phenomenon from the particular animal species showing the response to other mammals, including humans.

For styrene, however, it is clear that the processes responsible for the tumorigenesis observed in mice do not occur in rats. It is not only that rats do not show a tumor impact of styrene inhalation (the hypothesized generality of which across mammals is the basis for inferring its relevance to humans), but also that the specific mode of action-the tissue-specific metabolic activation-is not present. In short, the proposed generalization of effects across mammals is contradicted. Moreover, there is no indication that the mode of action would be present in humans, either.

To bring together experimental animal, human, and mode-of-action data into an overall weight-of-evidence conclusion about the potential for human carcinogenicity, one seeks to characterize the likelihood of a common thread that ties together the evidence from the different sources and proposes a biologically plausible line of reasoning as to why a potential hazard in humans is indicated. For styrene, there is no such commonality. The mouse tumor responses are best interpreted as a species-specific phenomenon that does not apply to rats, so any "sufficiency" of animal evidence does not apply to all animals-and to the degree that it does not, its applicability to humans is also questionable, because one would have to propose why, against all available evidence, humans should be like the mice and not like the rats in their response to styrene. There are no consistent responses among the human data of the kind that one would expect if there were true biological causation. The diversity of proposed tumor endpoints in human studies raises more questions than it answers-why is it that styrene would affect some tumor responses in some studies, and other responses (requiring other modes of action) in other studies? If there were truly a mode of action of sufficient generality and broadness to cause such a variety of tumor responses in humans, why is there no sign of it - and why is there no indication of hematopoietic cancers-in rats or in mice? Taken together, these data do not support the characterization of styrene as "reasonably anticipated to be a human carcinogen" and styrene should not be listed in NTP's Report on Carcinogens.

\section{ACKNOWLEDGMENT}

This article was prepared with financial support to Gradient, a private environmental consulting firm, by the Styrene Information and Research Center (SIRC). The authors have the sole responsibility for the writing and contents of this article. We thank two anonymous reviewers whose comments improved this article.

\section{REFERENCES}

Alexander DD, Mink PJ, Adami HO, et al. 2007. The non-Hodgkin lymphomas: A review of the epidemiologic literature. Internat J Cancer 120(Suppl.12):1-39

Anttila A, Pukkala E, Riala R, et al. 1998. Cancer incidence among Finnish workers exposed to aromatic hydrocarbons. Internat Arch Occup Environ Health 71:187-93 


\section{Weight of Evidence for Styrene Carcinogenicity}

Beliles RP, Butala JH, Stock CR, et al. 1985. Chronic toxicity and three-generation reproduction study of styrene monomer in the drinking water of rats. Fundam Appl Toxicol 5:855-68

Boffetta P, Adami HO, Cole P, et al. 2009. Epidemiologic studies of styrene and cancer: A review of the literature. J Occup Environ Med 51(11):1275-87

Bond GG, Bodner KM, Olsen GW, et al. 1992. Mortality among workers engaged in the development or manufacture of styrene-based products - An update. Scand J Work Environ Health 18:145-54.

Boogaard PJ, de Kloe KP, Wong BA, et al. 2000. Quantification of DNA adducts formed in liver, lungs, and isolated lung cells of rats and mice exposed to $14 \mathrm{C}$-styrene by nose-only inhalation. Toxicol Sci 57:203-16

Brunnemann KD, Rivenson A, Cheng SC, et al. 1992. A study of tobacco carcinogenesis. XLVII. Bioassays of vinylpyridines for genotoxicity and for tumorigenicity in A/J mice. Cancer Lett 65:107-13

Carlson GP, Rivera AAP, and Mantick NA. 2001. Metabolism of the styrene metabolite 4vinylphenol by rat and mouse liver and lung. J Toxicol Environ Health, Part A 63:541-51

Carlson GP, Ullman M, and Mantick NA. 2002. 4-Vinylphenol-induced hepatotoxicity and pneumotoxicity in mice. Toxicol Pathol 30:565-9

Carlson GP. 2002. Effect of the inhibition of the metabolism of 4-vinylphenol on its hepatotoxicity and pneumotoxicity in rats and mice. Toxicology 179:129-36

Conti B, Maltoni C, Perino G, et al. 1988. Long-term carcinogenicity bioassays on styrene administered by inhalation, ingestion and injection and styrene oxide administered by ingestion in Sprague-Dawley rats and para-methylstyrene administered by ingestion in Sprague-Dawley rats and Swiss mice. Ann NY Acad Sci 534:203-34

Cruzan G, Bus JS, Hotchkiss J, et al. 2011. CYP2F2-generated metabolites, not styrene oxide, are a key event mediating the mode of action of styrene-induced lung tumors. Regul Toxicol Pharmacol 62:214-20

Cruzan G, Carlson GP, Johnson KA, et al. 2002. Styrene respiratory tract toxicity and mouse lung tumors are mediated by CYP2F-generated metabolites. Regul Toxicol Pharmacol 35:308-19

Cruzan G, Carlson GP, Turner M, et al. 2005. Ring-oxidized metabolites of styrene contribute to styrene-induced Clara cell toxicity in mice. J Toxicol Environ Health, Part A 68:229-37

Cruzan G, Cushman J, Andrews LA, et al. 1997. Subchronic inhalation studies of styrene in CD rats and CD-1 mice. Fundam Appl Toxicol 35:152-65

Cruzan G, Cushman J, Andrews LA, et al. 1998. Chronic toxicity/oncogenicity study of styrene in $\mathrm{CD}$ rats by inhalation exposure for 104 weeks. Toxicol Sci 46:266-81

Cruzan G, Cushman JR, Andrews LS, et al. 2001. Chronic toxicity/oncogenicity study of styrene in CD-1 mice by inhalation exposure for 104 weeks. J Appl Toxicol 21:185-98

Frentzel-Beyme R, Thiess AM, and Wieland R. 1978. Survey of mortality among employees engaged in the manufacture of styrene and polystyrene at the BASF Ludwigshafen works. Scand J Work Environ Health 4 (Suppl 2):231

Goodman JE. 2008. Comments on the Epidemiology Data Reviewed in the May 22, 2008 NTP Report on Carcinogens Draft Background Document for Styrene. Available at http: //ntp.niehs.nih.gove/files/SchweitzerACMA_Styrene508.pdf

Goodman, JE. 2009. Comments on the Review of Epidemiology Data in the NTP 12th Report on Carcinogens Draft Styrene Profile. Available at http://ntp.niehs.nih.gov/files/ 20090206Goodman.pdf

Green T, Lee R, Toghill A, et al. 2001a. The toxicity of styrene to the nasal epithelium of mice and rats: studies on the mode of action and relevance to humans. Chem-Biol Interact 137:185-202 


\section{R. Rhomberg et al.}

Green T, Toghill A, and Foster J. 2001b. The role of cytochrome P-450 in styrene induced pulmonary toxicity and carcinogenicity in the mouse. Toxicology 169:107-17

Green T. 2000. Pulmonary toxicity and carcinogenicity of trichloroethylene: Species differences and modes of action. Environ Health Perspect 108(Suppl.2):261-4

Haseman JK, Huff J, and Boorman GA. 1984. Use of historical control data in carcinogenicity studies in rodents. Toxicol Pathol 12:126-35

Hodgson JT and Jones RD. 1985. Mortality of styrene production, polymerization and processing workers at a site in northwest England. Scand J Work Environ Health 1:347-52

Hynes DE, DeNicola DB, and Carlson GP. 1999. Metabolism of styrene by mouse and rat isolated lung cells. Toxicol Sci 51:195-201

IARC. (International Agency for Research on Cancer). 2002. IARC Monographs on the Evaluation of Carcinogenic Risks to Humans. Volume 82: Some Traditional Herbal Medicines, Some Mycotoxins, Naphthalene and Styrene: Section on Styrene. World Health Organization (WHO), pp 437-550. IARC Press, Lyon, France

Jersey GC, Balmer MF, Quast MF, et al. 1978. Two-year Chronic Inhalation Toxicity and Carcinogenicity Study on Monomeric Styrene in Rats—Final Report. Dow Chemical Company, Midland, MI, USA

Johanson G, Ernstgard L, Gullstrand E, et al. 2000. Styrene oxide in blood, hemoglobin adducts, and urinary metabolites in human volunteers exposed to C-13(8)-styrene vapors. Toxicol Appl Pharmacol 168:36-49

Kogevinas M, Ferro G, Saracci R, et al. 1993. Cancer mortality in an international cohort of workers exposed to styrene. In: Sorsa M (ed), Butadiene and Styrene: Assessment of Health Hazards, pp 289-300. International Agency for Research on Cancer (IARC) Scientific Publications, Lyon, France

Kogevinas M, Ferro G, Andersen A, et al. 1994. Cancer mortality in a historical cohort study of workers exposed to styrene. Scand J Work Environ Health 20:251-61

Kolstad HA, Lynge E, Olsen J, et al. 1994. Incidence of lymphohematopoietic malignancies among styrene-exposed workers of the reinforced plastics industry. Scand J Work Environ Health 20:272-8

Kolstad HA, Juel K, Olsen J, et al. 1995. Exposure to styrene and chronic health effects: Mortality and incidence of solid cancers in the Danish reinforced plastics industry. Occup Environ Med 52:320-7

Lijinsky W. 1986. Rat and mouse forestomach tumors induced by chronic oral administration of styrene oxide. J Natl Cancer Inst 77:471-6

Loughlin JE, Rothman KJ, and Dreyer NA. 1999. Lymphatic and haematopoietic cancer mortality in a population attending school adjacent to styrene-butadiene facilities, 1963-1993. J Epidemiol Community Health 53:283-7

McMichael AJ, Spirtas R, Gamble JF, et al. 1976. Mortality among rubber workers: Relationship to specific jobs. J Occup Med 18:178-85

NCI (National Cancer Institute). 1979. Bioassay of Styrene for Possible Carcinogenicity (CAS No. 100-42-5). NCI-CG-TR-185. Carcinogenesis Testing Program, Bethesda, MD, USA

Nicholson WJ, Selikoff IJ, and Seidman H. 1978. Mortality experience of styrene-polystyrene polymerization workers. Initial findings. Scand J Work Environ Health 4 (Suppl 2):247-52

NTP (National Toxicology Program). 2008. Final Report on Carcinogens Background Document for Styrene. US Department of Health and Human Services, Public Health Service, Research Triangle Park, NC, USA

NTP. 2011. Report on Carcinogens, Twelfth Edition. US Department of Health and Human Services, Public Health Service, Research Triangle Park, NC, USA

Ponomarkov B and Tomatis L. 1978. Effects of long-term oral administration of styrene to mice and rats. Scand J Work Environ Health 4:127-35 


\section{Weight of Evidence for Styrene Carcinogenicity}

Ponomarkov V, Cabral JRP, Wahrendorf J, et al. 1984. A carcinogenicity study of styrene-7, 8-oxide in rats. Cancer Lett 24:95-101

Rhomberg LR. 2008. Comments on the Weight of Evidence Analysis of Epidemiology Data in the May 22, 2008 NTP Report on Carcinogens Draft Background Document for Styrene. Available at http://ntp.niehs.nih.gov/files/JMcKnightAttachment2.pdf

Rhomberg LR. 2009. The Weight of Evidence Does Not Support the NTP Draft Styrene Profile's Conclusion of "Reasonably Anticipated to be a Human Carcinogen." Available at http://ntp.niehs.nih.gov/files/20090206Rhomberg.pdf

Roycroft JH, Mast TJ, Ragan HA, et al. 1992. Toxicological effects of inhalation exposure to styrene in rats and mice. The Toxicologist 12:397

Ruder AM, Ward EM, Dong M, et al. 2004. Mortality patterns among workers exposed to styrene in the reinforced plastic boatbuilding industry: An update. AmJ Ind Med 45:165-76

Sarangapani R, Teeguarden JG, Cruzan G, et al. 2002. Physiologically based pharmacokinetic modeling of styrene and styrene oxide respiratory tract dosimetry in rodents and humans. Inhalation Toxicol 14(8):789-834

Sathiakumar N, Graff J, Macaluso M, et al. 2005. An updated study of mortality among North American synthetic rubber industry workers. Occup Environ Med 62:822-9

Schottenfeld D and Fraumeni JF, eds. 2006. Cancer Epidemiology and Prevention (Third Edition). Oxford University Press, New York, NY, USA

Shen S, Li L, Ding X, et al. 2011. Oxidative metabolism of styrene in Cyp2f2-null and Cyp2e1null mouse liver and lung microsomes. Toxicologist 120 (Suppl. 2). Presented at Society of Toxicology 50th Annual Meeting. March.

Sumner SCJ, Cattley RC, Asgharian B, et al. 1997. Evaluation of the metabolism and hepatotoxicity of styrene in F344 rats, B6C3F1 mice, and CD-1 mice following single and repeated inhalation exposures. Chem-Biol Interact 106:47-65

Vodicka P, Tuimala J, Stetina R, et al. 2004. Cytogenetic markers, DNA single-strand breaks, urinary metabolites, and DNA repair rates in styrene-exposed lamination workers. Environ Health Perspect 112:867-71

Wenker MA, Kezic S, Monster AC, et al. 2001. Metabolism of styrene in the human liver in vitro: Interindividual variation and enantioselectivity. Xenobiotica 31(2):61-72

Wong O, Trent LS, and Whorton MD. 1994. An updated cohort mortality study of workers exposed to styrene in the reinforced plastics and composites industry. Occup Environ Med 51:386-96 